\title{
Laparoscopic iliopubic tract repair to treat recurrent pediatric inguinal hernia
}

\author{
Sung Ryul Lee ${ }^{1}$ (D)
}

Received: 18 May 2021 / Accepted: 12 October 2021 / Published online: 25 October 2021

(C) The Author(s) 2021

\begin{abstract}
Background Congenital defects, such as open processus vaginalis and the canal of Nuck, are common causes of primary pediatric inguinal hernia (PIH). However, in some patients, PIH occurs via acquired defects rather than congenital defects. The most representative cause of PIH is recurrent hernia. Recurrent PIH is treated with high ligation (HL), which is the same method that is used to treat primary PIH. However, the re-recurrence rate of recurrent PIH is high. This study aimed to compare laparoscopic iliopubic tract repair (IPTR) with laparoscopic HL for the treatment of recurrent PIH after primary PIH repair.

Methods From June 2013 to March 2019, 126 patients (<10 years old) with recurrent PIH were retrospectively enrolled. Patients were divided into two groups according to the operative technique: laparoscopic HL (58 patients) and laparoscopic IPTR (68 patients). With HL, the hernial sac was removed and the peritoneum closed. With IPTR, iliopubic tract and transversalis fascia sutures were applied.

Results There were no cases of conversion to open surgery. Re-recurrence only occurred in the HL group; no patients in the IPTR group developed re-recurrence $(8.6 \%$ [5/58] vs. $0.0 \%$ [0/68], respectively; $p=0.044)$. The mean duration from reoperation to re-recurrence in these five patients was 10.6 months. Other surgical outcomes and complications did not differ between the two groups.
\end{abstract}

Conclusions Laparoscopic IPTR is an effective surgical treatment for reducing re-recurrence of recurrent PIH.

Keywords Pediatric inguinal hernia $\cdot$ Laparoscopy $\cdot$ Re-operation $\cdot$ Iliopubic tract $\cdot$ Re-recurrence

Pediatric inguinal hernia (PIH) is a common disease in children. The incidence of PIH is approximately $3-5 \%$ in term infants and $9-11 \%$ in preterm infants [1]. Congenital defects, including open processus vaginalis (PV) in males and open canal of Nuck $(\mathrm{CN})$ in females, account for most cases of primary PIH [1]. Moreover, PIH can be acquired in some patients, such as from recurrent hernia. Because PV and $\mathrm{CN}$ are closed in the first operation, recurrent PIH is classed as an acquired cause of PIH. The main treatment for primary PIH and recurrent PIH is high ligation (HL). There are few reports on the re-recurrence rate after re-operation for recurrent PIH, but re-recurrence rate has been reported high [2]. Treatment of primary PIH due to congenital defects

Sung Ryul Lee

kingsoss@naver.com

1 Department of Surgery, Damsoyu Hospital, 234 Hakdong-ro, Gangnam-gu, Seoul, Republic of Korea and recurrent PIH due to acquired defects involves different surgical methods.

PIH is usually treated in two ways: open repair or laparoscopic repair with HL. The recurrence rate after laparoscopic repair is $1.1-18.6 \%[3,4]$. There have been many reports of HL as a treatment for recurrent PIH [5, 6]. In addition, there have been many reports of tissue reinforcement of the internal ring as a treatment for recurrent PIH [7-9]. The rerecurrence rate of recurrent PIH ranges from 0.0 to $4.2 \%$ in previous studies, although the surgical method and followup period differed between studies [2, 5-8]. For treatment of adult recurrent inguinal hernia, large mesh implantation is recommended to reduce re-recurrence, which is distinct from primary inguinal hernia treatment [10], while prosthetic mesh should never be considered for recurrent PIH repair [1].

Laparoscopic repair is performed in the context of primary and recurrent PIH treatment. Two widely performed laparoscopic methods are used to treat recurrent PIH: 
laparoscopic transabdominal closure (LTAC) and laparoscopic percutaneous extraperitoneal closure (LPEC) [5-8]. There are differences between these methods in terms of presence or absence of hernial sac removal, use of absorbable versus non-absorbable ties, HL, and tissue reinforcement.

Despite several options being available, no general guidelines have been established for the treatment of recurrent PIH. Iliopubic tract repair (IPTR) is a tissue reinforcement method used for laparoscopic PIH treatment $[11,12]$. The iliopubic tract was first described by Alexander Thomson [13] and is identified as a thickening of the transversalis fascia running deep and parallel to the inguinal ligament [14]. Several reports have described the results of laparoscopic IPTR for the treatment of recurrent PIH [7, 9].

One previous report classified primary PIH and tailored surgery accordingly; however, this was a case of open surgical repair, not laparoscopic repair [15]. Unlike in adults, technical details affect recurrence rates in pediatric patients, because synthetic mesh is not used in PIH repair. The author hypothesized that IPTR for the treatment of recurrent PIH would reduce the rate of re-recurrence compared with HL, which is usual for primary PIH treatment. No studies have compared HL with IPTR for the treatment of recurrent PIH. Thus, this study aimed to compare IPTR with HL for the laparoscopic treatment of recurrent PIH.

\section{Materials and methods}

All procedures performed in studies involving human participants were in accordance with the ethical standards of our institutional and/or national research committee and with the 1964 Helsinki Declaration and its later amendments or comparable ethical standards. This study was approved by the Institutional Review Board of Damsoyu Hospital (DSY2021-001). Informed consent was obtained from patients' parents/guardians.

There are some cases on acquired PIH. The first example is recurrent PIH (Fig. 1A), which occurred after ligation of a congenital defect during primary repair. The second example is of a metachronous contralateral inguinal hernia (MCIH) (Fig. 1B), which occurred after identifying closed PV or CN during primary repair [16]. In our institution, laparoscopic repair is performed for both recurrent and primary PIH. In the present study, all patients underwent laparoscopic repair and there was no conversion to open repair.

\section{Inclusion and exclusion criteria}

This study retrospectively analyzed case records of 126 patients who presented with recurrent PIH from June 2013 to March 2019 at Damsoyu Hospital, Seoul, Republic of Korea. During the study period, 9,318 patients underwent
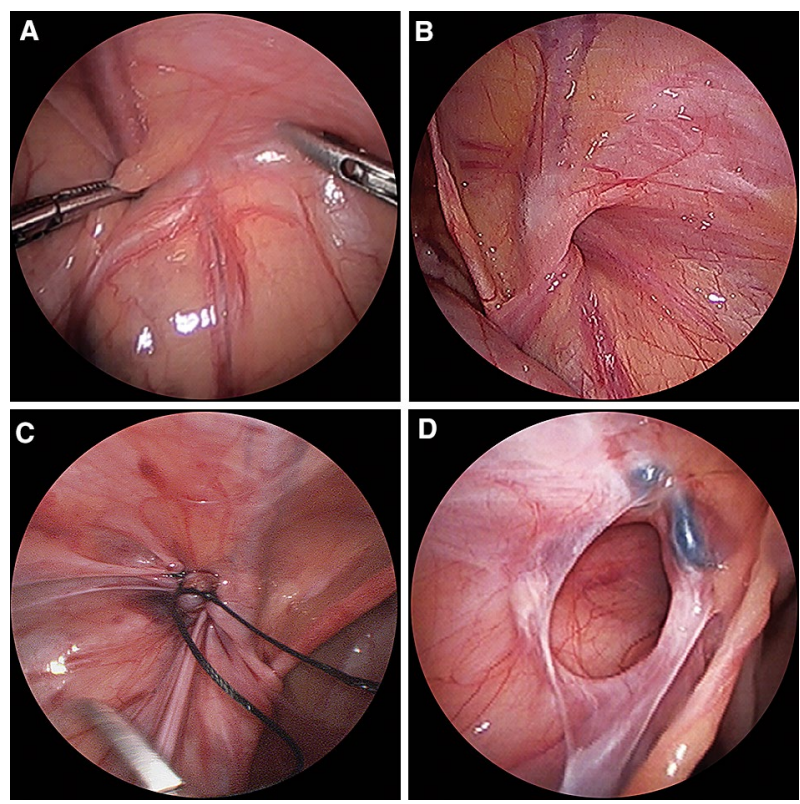

Fig. 1 Acquired PIH as recurrence and MCIH. A Closure of processus vaginalis during laparoscopic exploration 2 years ago. B MCIH developed 2 years later. C Laparoscopic repair of left inguinal hernia 11 months ago. D Recurrent PIH occurred 11 months later. PIH pediatric inguinal hernia; $M C I H$ metachronous contralateral inguinal hernia

laparoscopic repair for PIH. Of these patients, 9,036 had primary PIH. A total of 153 patients with $\mathrm{MCIH}$ were excluded from the study. The inclusion criteria included re-operation at our hospital, regardless of whether the primary operation was performed at our hospital or not. The exclusion criteria included re-operation at an outside hospital. Three patients with recurrent PIH underwent primary repair at our hospital, but they were excluded from this study because of follow-up loss. A total of 126 patients were finally analyzed (Fig. 2), including patients who underwent open or laparoscopic primary repair, either at our hospital $(N=19)$ or at other hospitals $(N=107)$.

\section{Group classification}

From June 2013 to September 2016, children underwent laparoscopic HL for the treatment of recurrent PIH. Rerecurrence was observed in two patients until September 2016; the treatment method was then changed to laparoscopic IPTR for recurrent PIH beginning in October 2016. Each patient's history and surgical method were confirmed by checking the medical records obtained from the facility at which the initial procedure had been performed. All data were retrospectively collected by a data manager at our research center. After the removal of the hernia sac, the hernia defect size was measured using the length of the laparoscopic instrument tip. We compared demographic and 
Fig. 2 Selection of patients with recurrent PIH. PIH pediatric inguinal hernia

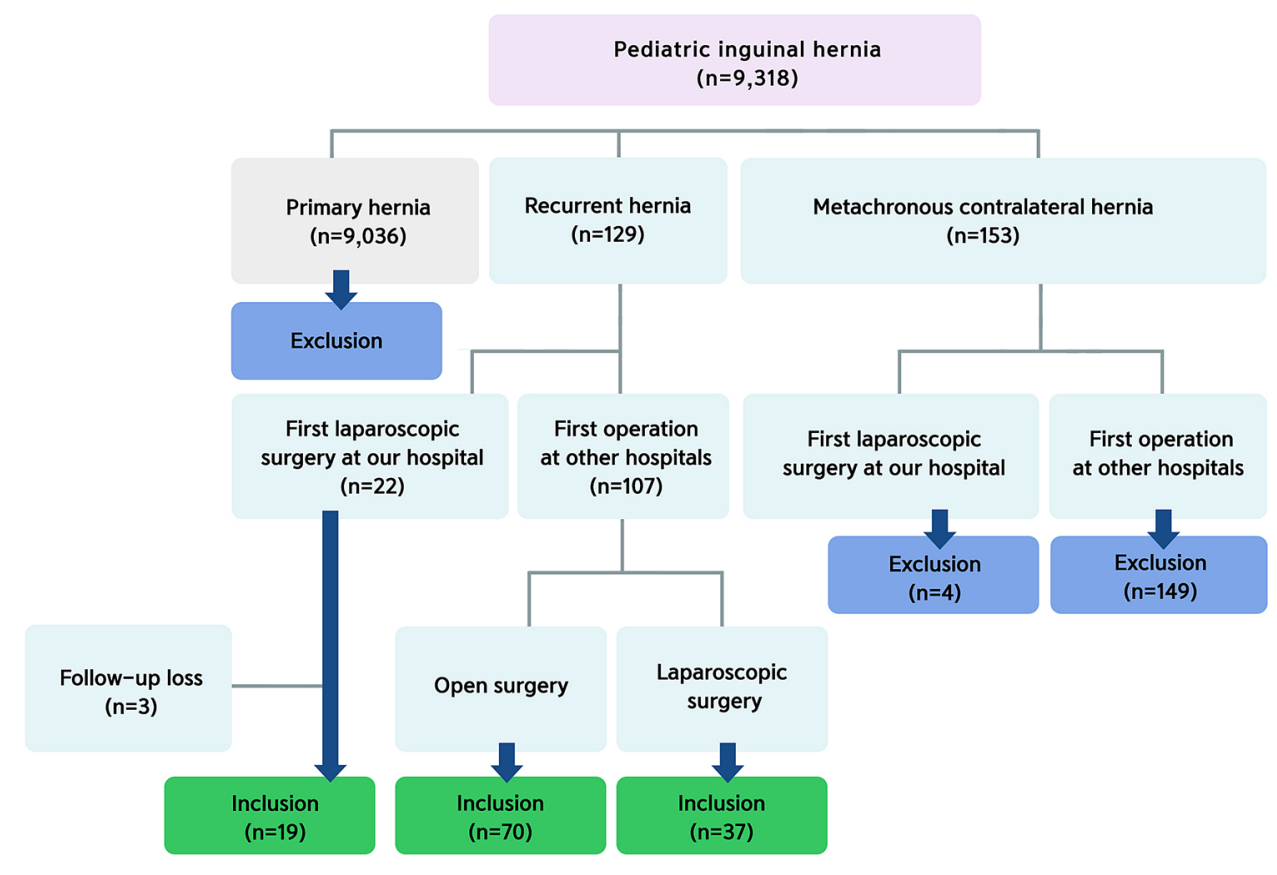

surgical outcomes between the IPTR and HL groups. We analyzed the primary operative method, hernial laterality, protruded organs, duration from first operation to re-operation, operation time, length of hospital stay, complications, and re-recurrence rate.

\section{Laparoscopic IPTR technique}

All procedures were performed under general anesthesia with patients in the supine position. Laparoscopic repair was performed using a three-port technique. The laparoscopy system included a $3.0-\mathrm{mm}$ camera and $3.0-\mathrm{mm}$ instruments. A transumbilical 3.0-mm incision was made, and a 3.0-mm trocar was used to create carbon dioxide pneumoperitoneum that was maintained at $6-8 \mathrm{mmHg}$. Two other 3.0-mm instruments were inserted through separate $3.0-\mathrm{mm}$ stab incisions bilaterally on the abdomen. With HL surgery, the hernial sac was removed and the peritoneum closed. The whole process of laparoscopic IPTR is shown in Fig. 3. The hernial sac was incised at the lateral site of the entrance to the internal inguinal ring. After separating the vas deferens and spermatic cord from the hernial sac by gentle retraction, the entire hernial sac was removed. In female patients, the round ligament was separated from the hernial sac and preserved. Dissecting the hernial sac revealed the anatomy of the hernia. Suture was performed when the iliopubic tract on the inferolateral side of the internal inguinal ring and the transversalis abdominis muscle arch on the superomedial side were identified. The iliopubic tract was sutured using non-absorbable 3-0 silk suture, as previously reported [11].

\section{Statistical methods}

All statistical analyses were performed using R software version 3.6.1 (R Development Core Team, Vienna, Austria; http://www.R-project.org). Continuous variables are presented as mean and range, whereas categorical variables are presented as frequency and percentage. The Wilcoxon rank-sum test was used to test for normality of continuous variables. Fisher's exact test or the $\chi^{2}$ test was used for categorical variables. A $p$ value threshold of 0.05 was chosen, and any univariate $p$ value of $\leq 0.05$ was considered statistically significant. Finally, odds ratios were calculated using Fisher's exact test and logistic regression.

\section{Results}

Patients' characteristics are shown in Table 1. All patients with recurrent PIH had indirect hernia. There were no differences in age, sex, body weight, primary operative method, hernial laterality, defect size, or herniated organ between the two groups. The duration from the first operation to re-operation was 13.9 months (range: 1-96 months) in the HL group and 20.2 months (range: $0.3-80$ months) in the IPTR group. All recurrent PIH cases were of indirect hernia. The surgical outcomes are shown in Table 2. There were no differences in operation time, length of hospital stay, or complications between the two groups. Re-recurrence only occurred in the HL group; no patients in the IPTR group developed re-recurrence $(8.8 \%$ [5/57] vs. $0.0 \%$ [0/63], respectively). HL was a significant risk factor for re-recurrence $(p=0.044)$. The 

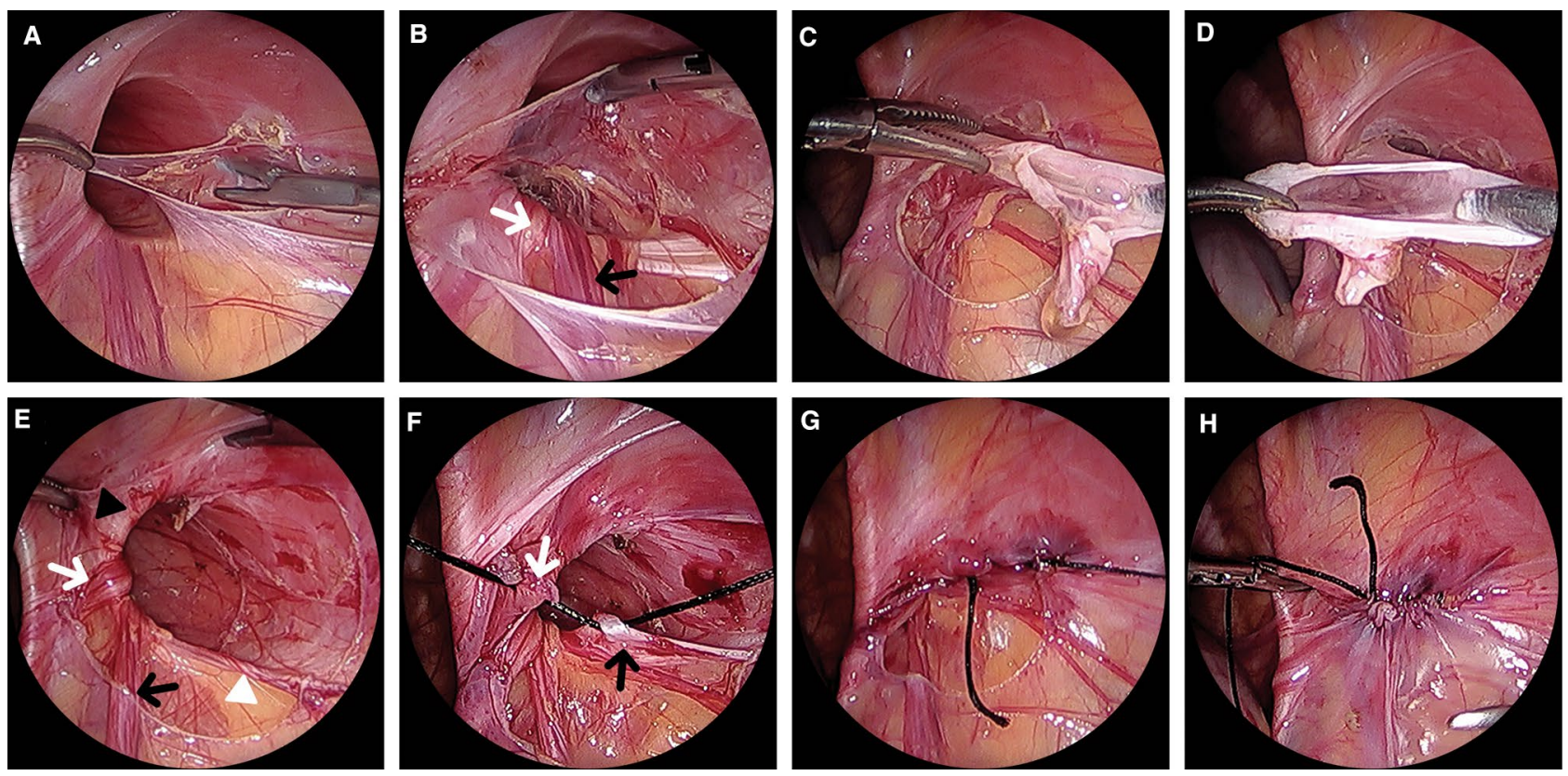

Fig. 3 IPTR procedure. A The hernial sac was incised at the lateral side of the internal inguinal ring. B The vas deferens (white arrow) and spermatic cord (black arrow) were separated from the hernial sac. C The entire hernial sac was transected. D The hernial sac was completely removed. E Internal inguinal ring: the iliopubic tract (white arrowhead) and the medial muscular arch of the transversalis

abdominis (black arrowhead). Preservation of the vas deferens (white arrow) and spermatic cord (black arrow). F First stitch of iliopubic tract repair. Iliopubic tract (black arrow) and medial muscular arch of the transversalis fascia suture (white arrow). G Completion of IPTR. H Complete peritoneal repair. IPTR iliopubic tract repair

mean duration from re-operation to re-recurrence in these five patients was 10.6 months. Three patients developed rerecurrence within 1 year after re-operation, and the remaining two patients developed re-recurrence 21 and 22 months after re-operation, respectively.

\section{Specific appearance of recurrent PIH}

We experienced an acquired hernia defect in recurrent $\mathrm{PIH}$ repair. In some cases, there was an acquired hernial sac in addition to the congenital hernial sac (Fig. 4A). This shows that the congenital defect was closed in the first operation, but another hernial sac formed as an acquired hernia defect developed, which supports the notion that recurrent PIH is caused by an acquired defect. In addition, as the internal ring is widened during recurrent PIH repair, there is sometimes no loosened hernia sac observed when the hernial sac is pulled into the abdominal cavity (Fig. 4B). This situation is different from that of the typical congenital patent PV.

\section{Discussion}

Most cases of PIH are caused by congenital defects due to open PV or CN. However, PIH can also occur due to acquired opening of the internal inguinal ring. Using the

Nyhus classification system, PIH is classified as Nyhus type 1 (congenital patent PV) [17], while recurrent PIH is the caused by an acquired defect. This supports that re-operation of recurrent PIH should be different from that of primary PIH.

Laparoscopic PIH repair is performed using various methods. Many methods are used to treat the hernial sac, including complete peritoneal disconnection, but not removal; hernial sac removal; and neither peritoneal disconnection nor hernial sac removal [18]. The recurrence rate is low with sac disconnection and removal surgery according to previous studies $[19,20]$. In the present study, hernial sac removal was performed in both the HL group and the IPTR group. In terms of the suture material, two materials are often used: absorbable tie and non-absorbable tie. One study indicated that use of non-absorbable suture decreases the rate of recurrence [21]. In the present study, non-absorbable suture was used in both groups. Many reports have compared open repair with laparoscopic repair for PIH treatment, and there appears to be no difference in the rate of recurrence between these approaches [22, 23].

Laparoscopic PIH repair uses different approaches for LTAC and LPEC, but these two methods cannot be compared by simple differences in their approaches, since the technical details of these procedures, including sac treatment, suture material, and suture method, are very different. 
Table 1 Patient demographics

\begin{tabular}{|c|c|c|c|}
\hline & $\begin{array}{l}\mathrm{HL} \\
(N=58)\end{array}$ & $\begin{array}{l}\text { IPTR } \\
(N=68)\end{array}$ & $p$ value* \\
\hline Age at re-operation (months) ${ }^{\mathbf{a}}$ & $45.4 \pm 30.5(2-118)$ & $44.2 \pm 32.1(3-119)$ & 0.805 \\
\hline Sex & & & 0.552 \\
\hline Male & $51(87.9 \%)$ & $63(92.6 \%)$ & \\
\hline Female & $7(12.1 \%)$ & $5(7.4 \%)$ & \\
\hline Body weight $(\mathrm{kg})^{\mathrm{a}}$ & $16.6 \pm 6.9(5.0-35.0)$ & $18.6 \pm 12.2(4.5-83.0)$ & 0.784 \\
\hline $\begin{array}{l}\text { Interval from first operation to re- } \\
\text { operation (months) }\end{array}$ & $13.9 \pm 16.9(1.0-96.0)$ & $20.2 \pm 19.8(0.3-80.0)$ & 0.099 \\
\hline Operative method at first operation & & & 0.232 \\
\hline Open & $31(53.5 \%)$ & $26(38.2 \%)$ & \\
\hline \multicolumn{4}{|l|}{ Laparoscopy } \\
\hline Extraperitoneal & $18(31.0 \%)$ & $28(41.2 \%)$ & \\
\hline Intracorporeal & $9(15.5 \%)$ & $14(20.6 \%)$ & \\
\hline Laterality & & & 0.203 \\
\hline Right & $31(53.4 \%)$ & $45(66.2 \%)$ & \\
\hline Left & $27(46.6 \%)$ & $23(33.8 \%)$ & \\
\hline Herniated organs & & & 0.781 \\
\hline Bowel & $14(24.1 \%)$ & $13(19.1 \%)$ & \\
\hline Ovary & $1(1.7 \%)$ & $1(1.5 \%)$ & \\
\hline Omentum & $43(74.2 \%)$ & $54(79.4 \%)$ & \\
\hline $\begin{array}{l}\text { Defect size }(\mathrm{cm})^{\mathrm{a}} \\
\text { (Diameter of deep inguinal ring) }\end{array}$ & $1.8 \pm 0.3(1.5-2.5)$ & $1.9 \pm 0.3(1.7-2.9)$ & 0.109 \\
\hline Follow-up period (months) ${ }^{\mathrm{a}}$ & $71.1 \pm 12.2(56-95)$ & $39.7 \pm 8.8(26-55)$ & $<0.001$ \\
\hline
\end{tabular}

$H L$ high ligation; IPTR iliopubic tract repair

Values are presented as mean \pm standard deviation or number $(\%)$

${ }^{*} \chi^{2}$ test or Fisher's exact test

${ }^{\mathrm{a}}$ Wilcoxon rank-sum test

Table 2 Surgical outcomes

\begin{tabular}{llll}
\hline & $\begin{array}{l}\text { HL } \\
(N=58)\end{array}$ & $\begin{array}{l}\text { IPTR } \\
(N=68)\end{array}$ & $p$ value* $^{*}$ \\
\hline${\text { Operation time }(\mathrm{min})^{\mathrm{a}}}^{\mathrm{a}}$ & $16.8 \pm 5.9(9-29)$ & $18.5 \pm 7.2(9-35)$ & 0.392 \\
${\text { Postoperative hospital stay }(\mathrm{h})^{\mathrm{a}}}_{\text {Complication }}$ & $10.6 \pm 9.0(4-48)$ & $8.5 \pm 4.1(5-30)$ & 0.618 \\
Hematoma & $2(3.4 \%)$ & $2(2.9 \%)$ & 0.987 \\
Seroma & 1 & 1 & \\
Wound infection & 1 & 1 & \\
Intraabdominal organ injury & 0 & 0 & 0.427 \\
Chronic inguinodynia & 0 & 0 & \\
Atrophic testis & 0 & 0 & 0.044 \\
Return to normal activity & 0 & 0 & N/A \\
(Postoperative day) $^{\mathrm{a}}$ & $3.5 \pm 1.1(2-6)$ & $3.4 \pm 1.2(2-5)$ & \\
Re-recurrence, N (\%) & $5(8.6 \%)$ & $0(0.0 \%)$ & \\
Re-recurrence period (months) & $10.6 \pm 9.6(3-22)$ & & \\
\hline
\end{tabular}

* $\chi^{2}$ test or Fisher's exact test

${ }^{a}$ Wilcoxon rank-sum test

The sac treatment, suture material, and suture method should be the same in order to fairly compare open repair surgery with laparoscopic repair in $\mathrm{PIH}$ treatment. To compare
LPEC with LTAC in PIH treatment, it is necessary to compare the technical details. For example, in one paper 

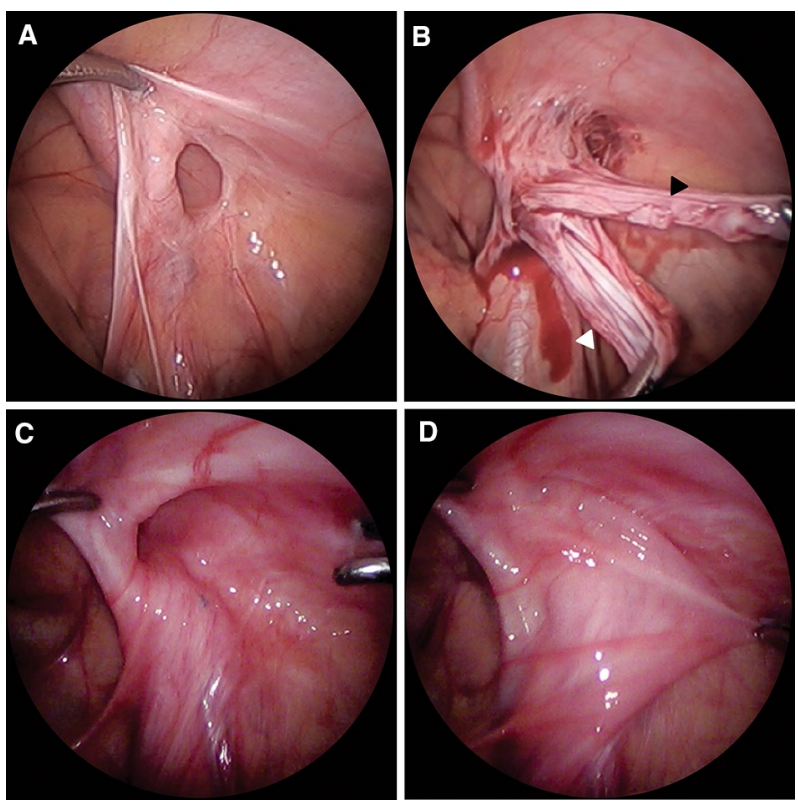

Fig. 4 Specific appearance of recurrent PIH. A Recurrent PIH. B Two hernial sacs were observed due to formation of another peritoneal hernial sac (black arrowhead) in addition to the hernial sac (white arrowhead) that was not removed during the first operation. $\mathbf{C}$ The internal ring was widened. D When the hernial sac was pulled into the abdominal cavity, no loosened hernial sac was observed. PIH pediatric inguinal hernia

comparing LPEC with LTAC [24], the suture material affected the rate of recurrence.

As an open approach, IPTR has been applied for the treatment of adult inguinal hernia for decades. There have been many reports of primary PIH and recurrent PIH treated using the laparoscopic approach $[7,11,12$, 25]. However, there are several concerns about IPTR. The first is injury to the vas deferens and spermatic cord when removing the hernial sac [26]. We encountered no intraoperative major bleeding or vas deferens injury due to removal of the hernial sac while separating the vas deferens and spermatic cord from the hernial sac (Fig. 3). The first stitch was sutured with a space for the vas deferens and spermatic cord to pass through (Fig. 3). The second concern is pain due to tension caused by suture. However, pain is difficult to assess in pediatric patients. In studies of laparoscopic IPTR, there was no difference in pain between patients who underwent HL and those who underwent IPTR $[11,12]$. The third concern is nerve injury. The entry point of the femoral branch of the genitofemoral nerve is in the caudal location of the inguinal ligament in $84.0 \%$ of patients and in the medial direction in the anterior superior iliac spine in $5.2 \%$ of patients [27]. Therefore, when suturing the iliopubic tract, sutures should be placed as close as possible to the inguinal ring. The fourth concern is technical difficulty. One report suggested no difference in operation time between HL and IPTR in laparoscopic repair of primary PIH [11]. In this study, which used laparoscopic repair for recurrent $\mathrm{PIH}$, there was no difference in operation time between HL and IPTR. At the beginning of this study, laparoscopic IPTR took 25-30 min, but over 100 cases, the operation took 10-15 min. Thus, laparoscopic IPTR poses a learning curve, but it is not difficult.

The suture approach is comprised of three stages in laparoscopic re-operation for recurrent PIH: simple HL without disconnection of the distal hernial sac, transection and removal of the hernial sac (the advanced stage), and removal of the hernial sac and IPTR (the most advanced stage). In some reports, the rate of recurrence after laparoscopic IPTR for the treatment of primary PIH was low [11, 25]. In the present study, HL was a significant risk factor for rerecurrence after laparoscopic repair of recurrent PIH. Five patients in the HL group developed re-recurrence, while no patients in the IPTR group developed re-recurrence. Postoperative complications did not differ between groups in this study.

This study has several limitations, including its retrospective design. The follow-up period differed between the two groups in this study. However, all five cases of re-recurrence developed in the HL group within 22 months, and 26 months have passed since the last patient was treated in the IPTR group. Thus, the effect of this difference in the follow-up period is expected to be minimal. Because the follow-up period was short, longer follow-up is required to ascertain the actual re-recurrence rate. All operations were performed by a single surgeon, and there were no changes in operative facilities during the study period. Therefore, IPTR may be considered an effective operation that does not increase the complication rate and that reduces re-recurrence in the treatment of recurrent PIH. Because this study was a singlecenter study, further multi-center studies are needed in the future.

In conclusion, IPTR significantly reduces the re-recurrence rate of recurrent PIH compared with HL. Therefore, laparoscopic IPTR is an effective and safe laparoscopic treatment for recurrent PIH.

Acknowledgements The author thanks Hyejin Park for performing the primary English grammar correction of this manuscript. The author also thanks Beom Seok Oh and Young Hyun Lee from the research center of Damsoyu Hospital for assisting with the statistical analysis and organizing the data in this manuscript. My thanks extend to Emily Woodhouse, $\mathrm{PhD}$, and Kelly Zammit, BVSc, from Edanz Group (https://edanz.com/ac), for editing a draft of this manuscript.

Funding This research did not receive any specific grant from funding agencies in the public, commercial, or not for profit sectors. 


\section{Declarations}

Disclosures Sung Ryul Lee has no conflicts of interest or financial ties to disclose.

Ethical approval This study was approved by the Institutional Review Board of Damsoyu Hospital (DSY-2021-001).

Open Access This article is licensed under a Creative Commons Attribution 4.0 International License, which permits use, sharing, adaptation, distribution and reproduction in any medium or format, as long as you give appropriate credit to the original author(s) and the source, provide a link to the Creative Commons licence, and indicate if changes were made. The images or other third party material in this article are included in the article's Creative Commons licence, unless indicated otherwise in a credit line to the material. If material is not included in the article's Creative Commons licence and your intended use is not permitted by statutory regulation or exceeds the permitted use, you will need to obtain permission directly from the copyright holder. To view a copy of this licence, visit http://creativecommons.org/licenses/by/4.0/.

\section{References}

1. Turnage RH, Richardson KA, Li BD, McDonald JC (2021) Abdominal wall, umbilicus, peritoneum, mesenteries, omentum, and retroperitoneum. In: Townsend CM, Beauchamp RD, Evers BM, Mattox KL (eds) Sabiston textbook of surgery, 21st edn. Elsevier, Amsterdam, pp 1868-1869

2. Koivusalo AI (2017) A review of the incidence, manifestation, predisposing factors, and management of recurrent pediatric inguinal hernia. Eur J Pediatr Surg 27:478-483

3. Morini F, Dreuning K, Janssen Lok M, Wester T, Derikx J, Friedmacher F, Miyake H, Zhu H, Pio L, Lacher M, Sgró S, Zani A, Eaton S, van Heurn E, Pierro A (2021) Surgical management of pediatric inguinal hernia: a systematic review and guideline from the European Pediatric Surgeons' Association Evidence and Guideline Committee. Eur J Pediatr Surg. https://doi.org/10.1055/s-00401721420, Feb10

4. Kilda A, Berzanskis M, Lukosiute-Urboniene A, Malcius D, Barauskas V (2020) High recurrence rate of children's inguinal hernia after percutaneous internal ring suturing: a single-center study. Hernia. https://doi.org/10.1007/s10029-020-02316-1,Oct7

5. Shalaby R, Ismail M, Gouda S, Yehya AA, Gamaan I, Ibrahim R, Hassan S, Alazab A (2015) Laparoscopic management of recurrent inguinal hernia in childhood. J Pediatr Surg 50:1903-1908

6. Hayashi K, Ishimaru T, Kawashima H (2019) Reoperation after laparoscopic inguinal hernia repair in children: a retrospective review. J Laparoendosc Adv Surg Tech A 29:1264-1270

7. Lee SR, Park PJ (2019) Laparoscopic reoperation for pediatric recurrent inguinal hernia after previous laparoscopic repair. Hernia 23:663-669

8. Zhu H, Li J, Peng X, Alganabi M, Zheng S, Shen C, Dong K (2019) Laparoscopic percutaneous extraperitoneal closure of the internal ring in pediatric recurrent inguinal hernia. J Laparoendosc Adv Surg Tech A 29:1297-1301

9. Shehata SM, ElBatarny AM, Attia MA, El Attar AA, Shalaby AM (2015) Laparoscopic interrupted muscular arch repair in recurrent unilateral inguinal hernia among children. J Laparoendosc Adv Surg Tech A 25:675-680

10. Bittner R, Arregui ME, Bisgaard T, Dudai M, Ferzli GS, Fitzgibbons RJ, Fortelny RH, Klinge U, Kockerling F, Kuhry E, Kukleta J, Lomanto D, Misra MC, Montgomery A, Morales-Conde S, Reinpold W, Rosenberg J, Sauerland S, Schug-Pa $\beta$ C, Singh K, Timoney
M, Weyhe D, Chowbey P (2011) Guidelines for laparoscopic (TAPP) and endoscopic (TEP) treatment of inguinal hernia [International Endohernia Society (IEHS)]. Surg Endosc 25:2773-2843

11. Lee SR, Park PJ (2021) Adding iliopubic tract repair to high ligation reduces recurrence risk in pediatric laparoscopic transabdominal inguinal hernia repair. Surg Endosc 35:216-222

12. Lee SR (2018) Benefits of laparoscopic posterior wall suture repair in treating adolescent indirect inguinal hernias. Hernia 22:653-659

13. Thomson A (1836) Cause anatomique de la hernie inguinale externe. J Conn Med Part 4:147

14. Teoh LS, Hingston G, Al-Ali S, Dawson B, Windsor JA (1999) The iliopubic tract: an important anatomical landmark in surgery. J Anat 194:137-141

15. Shehata S, Shehata S, Wella HL, Abouheba M, Elrouby A (2018) Pediatric inguinal hernias, are they all the same? A proposed pediatric hernia classification and tailored treatment. Hernia 22:941-946

16. Watanabe T, Yoshida F, Ohno M, Mori M, Tomita H, Ukiyama E, Nakano M, Endo M (2016) Morphology-based investigation of metachronous inguinal hernia after negative laparoscopic evaluation - is it acquired indirect inguinal hernia? J Pediatr Surg $51: 1548-1551$

17. Nyhus LM (1993) Individualization of hernia repair: a new era. Surgery 114:1-2

18. Lukong CS (2012) Surgical techniques of laparoscopic inguinal hernia repair in childhood: a critical appraisal. J Surg Tech Case Rep 4:1-5

19. Abd-Alrazek M, Alsherbiny H, Mahfouz M, Alsamahy O, Shalaby R, Shams A, Elian A, Ashour Y (2017) Laparoscopic pediatric inguinal hernia repair: a controlled randomized study. J Pediatr Surg 52:1539-1544

20. Marte A, Sabatino MD, Borrelli M, Parmeggiani P (2009) Decreased recurrence rate in the laparoscopic herniorraphy in children: comparison between two techniques. J Laparoendosc Adv Surg Tech A 19:259-262

21. Grimsby GM, Keays MA, Villanueva C, Bush NC, Snodgrass WT, Gargollo PC, Jacobs MA (2015) Non-absorbable sutures are associated with lower recurrence rates in laparoscopic percutaneous inguinal hernia ligation. J Pediatr Urol. https://doi.org/10.1016/j. jpurol.2015.04.029,Jun14

22. Nakashima M, Ide K, Kawakami K (2019) Laparoscopic versus open repair for inguinal hernia in children: a retrospective cohort study. Surg Today 49:1044-1050

23. Rao R, Smith M, Markel TA, Gray BW, Landman MP (2021) Modified percutaneous internal ring suturing with peritoneal injury in children: matched comparison to open hernia repair. Surg Endosc 35:854-859

24. Wang D, Yang P, Yang L, Jin S, Yang P, Chen Q, Tang X (2020) Comparison of laparoscopic percutaneous extraperitoneal closure and laparoscopic intracorporeal suture in pediatric hernia repair. J Pediatr Surg. https://doi.org/10.1016/j.jpedsurg.2020.11.022,Nov27

25. Tsai YC, Da Lin C, Chueh SC (2015) Technical refinement of mini-laparoscopic hernia repair in infants and children. Hernia 19:599-604

26. Bouchot O, Branchereau J, Perrouin-Verbe MA (2018) Influence of inguinal hernia repair on male fertility. J Visc Surg 155:S37-S40

27. Reinpold W, Schroeder AD, Schroeder M, Berger C, Rohr M, Wehrenberg U (2015) Retroperitoneal anatomy of the iliohypogastric, ilioinguinal, genitofemoral, and lateral femoral cutaneous nerve: consequences for prevention and treatment of chronic inguinodynia. Hernia 19:539-548

Publisher's Note Springer Nature remains neutral with regard to jurisdictional claims in published maps and institutional affiliations. 